\title{
Distinguished Career Award for Excellence in Teaching and Educational Scholarship
}

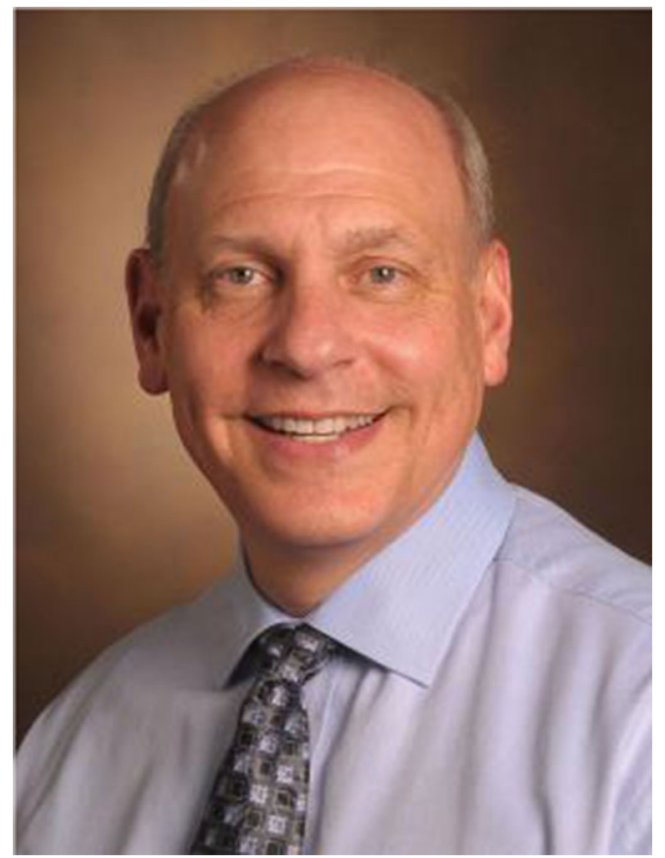

This award recognizes an IAMSE member who has a distinguished record of educational scholarship, including educational research and dissemination of scholarly approaches to teaching and education. Candidates should be Professor, Associate Professor, or equivalent rank, or have demonstrated greater than 10 years of educational scholarship. Additionally, candidates must have a significant record of engagement within IAMSE. Award recipients are selected based on the impact, ingenuity, and longevity of educational scholarship and their records of publications, presentations, and other forms of dissemination of educational scholarship. IAMSE members may selfnominate or be nominated by another IAMSE member.
The Educational Scholarship Committee reviews all nominations and supporting documentation based on established criteria and selects finalists. Final selection of each award recipient rests with the Awards Committee.

\section{Award Winner - Neil Osheroff, PhD}

Director, Academy for Excellence in Education, Vanderbilt University School of Medicine, USA

Neil Osheroff received his $\mathrm{PhD}$ in Biochemistry and Molecular Biology from Northwestern University and was a Helen Hay Whitney Foundation Fellow at the Stanford University School of Medicine. He currently is Professor of Biochemistry and Medicine at the Vanderbilt University School of Medicine and holds the John G. Coniglio Chair in Biochemistry. In addition to directing his research laboratory, he is committed to educating future generations of health professionals and to the professional development of medical science educators. He has been a School of Medicine course director since 1990 and was one of four faculty members tasked with developing and implementing the pre-clerkship phase of the medical curriculum as part of a major revision in 2013. He currently co-leads the preclerkship phase and chairs the phase's teaching team. He also directs the School of Medicine Academy for Excellence in Education and chairs the Master Science Teacher group.

Internationally, he is a Past-President of the Association of Biochemistry Educators and currently serves as the Treasurer of IAMSE.

He has received awards for mentoring, teaching, curricular design, educational leadership, and affirmative action, and is a Fellow of the American Association for the Advancement of Science. He has published more than 250 papers and has presented more than 300 scientific and educational talks in 31 different countries. 